\title{
The Use of Social Media to Promote Sustainable Fashion and Benefit Communications: A Data-Mining Approach
}

\author{
Li Zhao ${ }^{1}$, Stacy H. Lee ${ }^{2, *(\mathbb{D},}$, Muzhen $\mathrm{Li}^{1}$ and Peng Sun ${ }^{3}$ \\ 1 Textile and Apparel Management, University of Missouri, Columbia, MO 65211, USA; \\ zhaol1@missouri.edu (L.Z.); ml896@mail.missouri.edu (M.L.) \\ 2 Department of Hospitality and Retail Management, Texas Tech University, Lubbock, TX 79409, USA \\ 3 The Climate Corporation, San Francisco, CA 94103, USA; peng.sun1@bayer.com \\ * Correspondence: stacy.h.lee@ttu.edu
}

check for updates

Citation: Zhao, L.; Lee, S.H.; Li, M.; Sun, P. The Use of Social Media to Promote Sustainable Fashion and Benefit Communications: A Data-Mining Approach. Sustainability 2022, 14, 1178. https://doi.org/ $10.3390 /$ su14031178

Academic Editor: Andrea Pérez

Received: 23 December 2021

Accepted: 17 January 2022

Published: 20 January 2022

Publisher's Note: MDPI stays neutral with regard to jurisdictional claims in published maps and institutional affiliations.

Copyright: (c) 2022 by the authors. Licensee MDPI, Basel, Switzerland. This article is an open access article distributed under the terms and conditions of the Creative Commons Attribution (CC BY) license (https:// creativecommons.org/licenses/by/ $4.0 /)$.

\begin{abstract}
Numerous brands utilize social media to capture consumers' interests while promoting their sustainability goals. To understand how sustainable fashion brands communicate with their consumers, this study explored the visual and textual information sustainable fashion brands post on social media. Data were collected from sustainable fashion brands' social media pages, and a total of 1525 images and captions and 140,735 comments were analyzed. By employing color theory and the theory of speech acts, HSV color analysis and the SVM classification model were used to extract information. The results showed that the images and captions posted by all three brands were consistent with their brand identities and sustainability goals. We also found that there were significant differences among the three brands when comparing posts employing expressive and assertive acts with posts using directive and assertive acts. These results indicate that social media users are more likely to leave comments when they read posts containing expressive and directive acts. These findings will allow fashion social media marketers to select appealing images and colors to engage consumers as well as to choose appropriate speech acts to deliver information to achieve their sustainability goals.
\end{abstract}

Keywords: social media; data mining; color theory; speech act theory; sustainable fashion brand

\section{Introduction}

Social media presents opportunities for fashion brands to attract the attention of younger generations, build a brand image, and promote products [1]. Social media platforms allow for interactive experiences between brands and consumers, which makes social media one of the best ways to interest consumers in specific trends [2]. As consumers are now paying more attention to environmental and social concerns, many fashion brands, such as Patagonia, Everlane, Reformation, Stella McCartney, Veja, Tretorn, and Allbirds, actively communicate information regarding their environmentally sustainable and fair-trade products [3]. Therefore, fashion brands exploit social media by posting images and textual information that promote sustainability events and campaigns while demonstrating the beauty of the natural wild aligned with their products [4].

Although demands for sustainability are increasing (more than 50\% of Europeans claim that they are willing to pay a higher price for sustainable products), the final market share for sustainable products is ironically less than 1\% [5]. This emphasizes the importance of the words sustainable fashion brands choose to effectively compose their brand messages on social media to appeal to consumers interested in sustainability. Therefore, it is vital to explore how sustainable apparel brands utilize social media to advertise their products and services and engage with consumers to help these brands develop effective social media marketing and communication strategies.

Social media researchers usually focus on Facebook and Twitter, as these are the top two social media platforms used by marketers. However, businesses that depend heavily on 
visuals to advertise may find Instagram more beneficial in featuring their brands' products and thus increasing their value. Unlike Facebook, which focuses on connecting friends and family, Instagram's emphasis is on speaking through quality pictures. Therefore, as the role of both images and textual information is extremely important on social media platforms, this study suggests a better means to create visuals and text that can influence consumer responses, including their emotions, and emphasize specific topics in social media marketing. In this sense, based on color theory and the theory of speech acts, the objective of this study is to examine the visual and textual information posted by sustainable fashion brands, and further investigate the linguistic styles used by these brands when communicating with consumers.

\section{Literature Review}

\subsection{Fashion Brands' Social Media Communications and Sustainability Goals}

The advent of social media has shifted business-to-consumer communication from unidirectional to bidirectional. Social media has decreased the communication distance between consumers and brands, allowing fashion brands to share information and capture consumers' interest in specific trends [6]. Through social media interactions, companies gain users' insights faster, thus fostering brand loyalty by posting relevant and popular content [7]. Social media creates interactive experiences between brands and consumers, allowing consumers to engage with and remain current on information brands post [2]. Enabling consumers to share opinions about the products and services brands offer, consumers can choose to "like", "follow", or even leave comments and reviews on brands' social media pages. By exploiting social media, fashion brands strive to establish an online brand community, convey their value, and build a conscious brand image. Burberry was the first luxury fashion brand to invest in social media and reposition as more fashionable for young consumers [8]. Numerous luxury and high end brands use their Instagram accounts to form relationships with followers, which can positively impact their brand image [9]. Similarly, Roncha and Radclyffe-Thomas [10] found that Instagram is a strong medium for building brand communities and co-creating value for brands.

Likewise, sustainability has become an essential goal of businesses, governments, and nonprofits. To reflect these goals, Elkington [11] proposed a Triple Bottom Line (TBL) which integrates social, environmental, and economic factors (referring to profit, people, and the planet, respectively). Defined as "sustainable development that meets the needs of the present generations without compromising the ability of the future generations to meet their own needs" [12], sustainability emerged as a priority in the Brundtland Report published in 1987. Some studies have paid more attention to environmental areas [13] while others have only focused on the social aspects of sustainability. However, Elkington's [11] triple bottom line provides a method for assessing the performance of businesses and organizations from an economic, social, and environmental perspective [14].

Driven by an interest in sustainability, numerous fashion brands actively utilize social media as a medium to communicate sustainability information and/or develop a conscientious brand image [3]. One example is Everlane, which closely monitors and listens to customer feedback on business decisions like product launches, packaging design, and sustainability activities through their social media accounts [15]. A study by Reilly and Hynan [2] explored the relationship between corporate communication and sustainability by reviewing Everlane's annual reports from their social media accounts. De Lenne and Vandenbosch [16] studied the ways in which exposure to social media content affects individuals' cognition concerning sustainable apparel. Goh, Heng, and Lin [17] quantified the impact of community content posted by customers on social media on their apparel purchase expenditure through conducting a content analysis.

While many marketers utilize social media tools to understand communications with consumers, social media researchers have predominantly focused on Facebook and Twitter [18]. As social media provides rich information utilizing both visuals and text, there have been studies conducted to understand the emotional content of Twitter and Facebook 
posts [19]. Unlike Facebook, which focuses on connecting friends and family, Instagram emphasizes images while allowing users to supplement with text. For businesses in which visuals are imperative to shaping their brand image and introducing their products, Instagram may be more beneficial, as it allows these businesses to present images and photos portraying their products and values. Therefore, Ha, Kwon, Cha, and Joo [20] found that fashion tastes are shared and disseminated on Instagram by manually tagging fashion posts.

Yet, relatively few studies have analyzed how fashion brands communicate on social media and how potential customers respond to brands' posts. Social media communicates vast information through visuals and text. In addition to textual communication, most social media platforms feature image posts, and images communicate continuous signals through sets of discrete symbols or underlying hidden meanings. Through these images, consumers can extract the hidden meaning behind brands' messages and thus perceive the intended information, which can further stimulate brand images. Therefore, it is critical to understand how sustainable apparel brands utilize social media to communicate their brand images as sustainable through both visual and textual information. By analyzing both visual and textual information, this study aimed to explore how the colors used along with the textual features of fashion brands' posts influence customers' responses, particularly emotional, and to further examine the underlying meaning and intentions conveyed through the textual information in sustainable brands' posts.

\subsection{Color Theory and Social Media Communication}

To understand the visual information presented on social media and how it affects communications with followers, this study used color theory. Color theory is a practical guide to color mixing and the visual effects of specific color combinations [21]. Color is perceived by the eye but is interpreted by the brain. Different colors can be explained on the basis of three dimensions: hue, brightness (or value), and saturation (or chroma) [22]. As the main quality factor in color, hue is the degree to which a stimulus can be described as similar to or different from stimuli that are described as red, green, blue, and yellow. Depending on the complexity of the wavelength, saturation can be defined as the percentage of hue in a certain color which ranges from pure color to gray at a constant lightness level [23]. Luminosity describes the subject's brightness perception, which can be depicted as its main measurable trait, and signifies the extent of light reflected by a certain color [24].

Color plays a critical role in marketing communications, creating the visual equity of a brand, which guides $62 \%$ to $90 \%$ of purchasing decisions $[25,26]$. Color is known to be a significant contributor to building brand personality, which influences emotions (e.g., pleasure and excitement), cognition (e.g., value and connotation), and behavior (e.g., intention to approach or avoid), in a particular environment [27]. Due to the important role color plays in influencing every aspect of human perception, there have been a number of studies conducted on the role of color in diverse fields, such as psychology, sociology, cultural anthropology, neurology, and marketing [28]. More specifically, color studies have been widely used in architecture and environmental design [29], apparel product design [30], and photography [31].

Lichtlé [24] emphasized the impact of color associations on consumer behavior, while others have claimed that color research in marketing is still in its primary phase [32,33]. Previous studies have also explored the relationship between color and emotion among college students [34]. If the main color associated with a brand's image is consistent with the brand's identity, customers will accept the information conveyed by these images more readily. Amencherla and Varshney [19] studied the associations between the visual content features of images on social media and the psycholinguistic sentiment conveyed by their hashtag descriptions. Therefore, numerous studies have been conducted on role of color on emotions and behavior, but most studies have focused on a single color, an interior retail environment, or traditional communication mediums such as newspapers, magazines, and the colors of products [30]. For instance, blue stores convey the feeling 
of being relaxing, reliable, and less crowded, whereas food in red packages tends to be sweeter than food in blue packages [35]. In terms of product categories, functional products (e.g., car tires) are linked to blue, and red is associated with sensory or social products (e.g., chocolates) [25]. On the other hand, when red is featured in an online context, it may trigger impulsive buying, while blue environments activate more expensive purchases [36,37]. These examples demonstrate that consumer responses to products and communications can differ depending on the colors companies present.

The primary extant studies have mainly focused on investigating the effects of hue alone, thereby neglecting possible contradictory forces at play [38]. Within the three dimensions, saturation and brightness are also found to influence human perceptions of color more than, or at least equal to, hue [39]. Consequently, there are numerous studies on how color impacts affective, cognitive, and conation states, but there is far less empirical evidence on how the three dimensions of color influences brands' communications on social media. This gap emphasizes the importance of examining extracted visual information on the three dimensions of color, and how these dimensions can be associated with brands' sustainability efforts. Since color is a component of every form of pictorial communication, knowledge of color selections is critical for advertising practitioners, managers, and executives who are involved in corporate communications.

RQ1. How do fashion brands feature sustainability in the visual information they convey on social media?

\subsection{The Speech Act Theory and Social Media Communications}

The Speech Act Theory (SAT) [40] is one of the most influential linguistic theories guiding the process of textual analysis. The SAT posits that a speaker's underlying meaning and intentions are conveyed through words and sentences [41]. It provides a conceptual linguistic foundation for various functions of speech and helps gain comprehensive insight from textual datasets which state a fact as being either true or false [42]. Utterances denote the environments that motivate such utterances, presenting an indicative action, and such an indicative action is considered a performative sentence. The SAT explains how different languages can be used to understand what people hope to achieve through specific speech acts, and to detect the effects of utterances on audiences [43]. Accordingly, through various functions (e.g., language construction through words, sentences, and interactional exchanges), SAT can inspire behavioral changes in message receivers [44].

In order to identify a speaker's intent in an utterance, the SAT classifies speech acts into five broad categories: assertive, expressive, directive, commissive, and declarative [40]. Assertive acts consist of true or false information conveyed without emotion or valence (e.g., "we have launched our new product"). Therefore, marketers make assertive acts in an explicit manner and the utterance conveys their ideas or thoughts [45]. Expressive acts comprise affective phrases, such as desire for a product, appreciation, opinions, and so on ("Thanks for the award"). Expressive acts contain marketers' attitudes or manner, offering a blessing, apology, comfort, appreciation, or congratulations [45]. Directive acts contain phrases that issue calls to action or demands for information (e.g., "I wouldn't recommend you read it"). In a directive act, marketers and brands ask audiences to do something, such as giving advice or making a request or an appeal [45]. Commissive acts occur when the speaker assures, proposes, or indicates something upcoming, through presenting a negative or positive sentiment (e.g., "I will never read another book from this author" or "We will come back for sure"). In this sense, marketers and brands promise that their organization will do something, such as making a pledge or threat [45]. Declarational acts encompass autonomous decisions with direct consequences for the receiver (e.g., "You are fired") [44]. Brands and marketers do not have the authority to execute declarative acts directed towards consumers in brand communications.

In order to communicate substantial information in brand communications, marketers use language and images which contain their intentions and the desired relationship with their audience [46]. Unlike traditional media, social media's language not only transmits 
objective information and descriptions of reality but has also become a means to design a reality [47]. Compared with chats, reviews, and blogs, social media has limitations to pursuing rich information, thereby requiring precise communication that constructs, shares, and shapes visions, perceptions, and identities. Therefore, based on previous studies, commissive and declarational acts are less likely to be used in brand messages on social media [44]. In social media contexts, marketers and brand managers develop content that features objective information, appeals to consumers' emotions, or calls consumers to action, which mirrors assertive, expressive, and directive speech acts [40].

Moreover, Aleti et al. [48] investigated three categories of celebrities (chefs, selfmade fashion bloggers, and personal trainers) on Twitter, and found that a narrative style of linguistic communication is more impactful on word of mouth. By examining 45,000 consumer reviews, Ordenes et al. [43] explained the differential influences on activation levels (e.g., tentative language), imbedded sentiment expressions (e.g., commissive language), and conversation patterns (e.g., incoherence) on overall consumer emotions (i.e., star ratings). They found that positive (negative) directives and commissive acts had a stronger impact on overall sentiment strength than did assertive acts, and that implicit sentiment expressions frequently appeared in consumer reviews. Social media is one of the primary means to communicate with consumers and there have been numerous studies to help understand the impact of linguistic style on consumers' responses and emotions. As different types of social media platforms that feature either text only, text and images, or videos and interactive live videos emerge, it is important to understand how fashion brands communicate a sustainable identity to their target consumers via social media.

RQ2. What linguistic style of communication do fashion brands use to convey sustainability?

Figure 1 summarizes the information flow schema in social media regarding fashion sustainability communications. Fashion brands utilize both visual and textual information to convey their identities and values to consumers. Such information conveys the sustainability goals of fashion brands to social media users.

Social Media

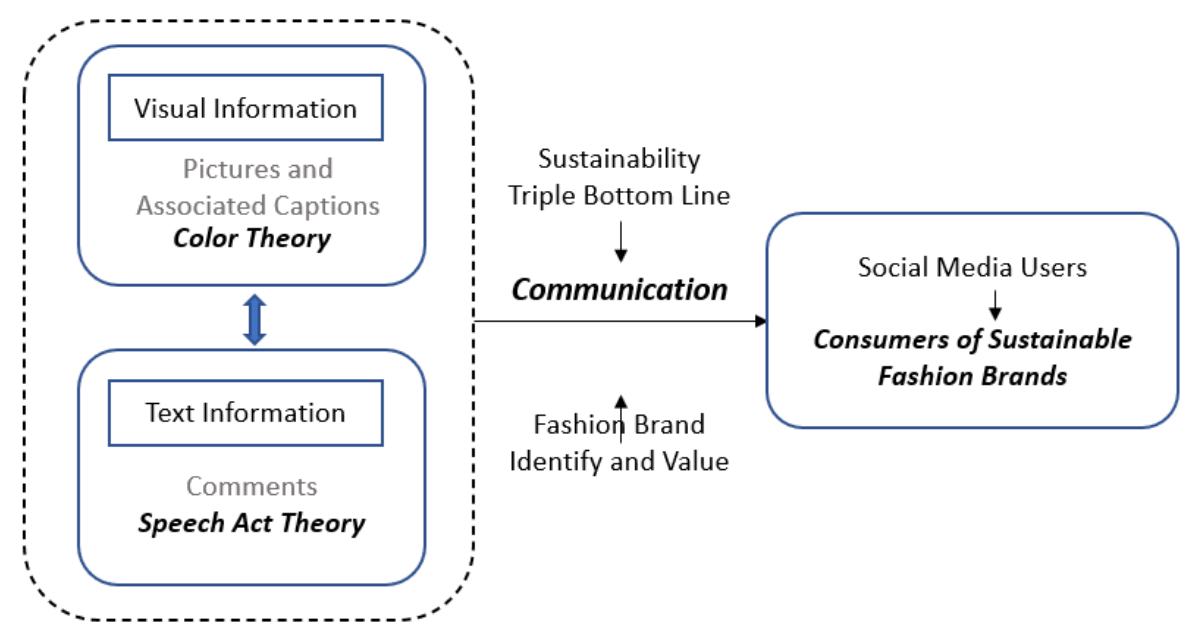

Figure 1. Information flow schema in social media regarding fashion sustainability communications.

\section{Data Collection}

Due to the nature of the research questions, this study designed a quantitative approach by utilizing social media data. Three sustainable fashion brands were chosen-Everlane, Patagonia, and Stella McCartney-representing contemporary casual, outdoor, and luxury brands. These companies are well-known for their sustainability practices, focusing on organic and recyclable materials, fair trade, reducing waste, chemicals, and plastics, fostering transparency, and connecting with environmental groups. These three brands' social media accounts, particularly their Instagram pages, were used to collect data. Essentially a photo-sharing network, Instagram was estimated to have more than one billion users 
worldwide in 2021 [49]. Instagram also allows for the use of hashtags to label topics, which has become a quintessential feature of social media.

As Figure 2 illustrates, a data-analysis pipeline was established to scrape images, caption content, and comments from each brand using the official Cloud API of their official brand Instagram accounts. Specifically, all visual and textual information posted during 2017 was extracted and inputted into the pipeline. Several images were excluded, as they only featured text without any image information. After cleaning the data, we leveraged several data-mining algorithms to analyze all images and text in the cloud. A total of 320 pictures and post captions were crawled from Everlane, 300 from Patagonia, and 905 from Stella McCartney. On the other hand, 140,735 comments were scraped: 24,055 from Everlane, 41,719 from Patagonia, and 74,961 from Stella McCartney.

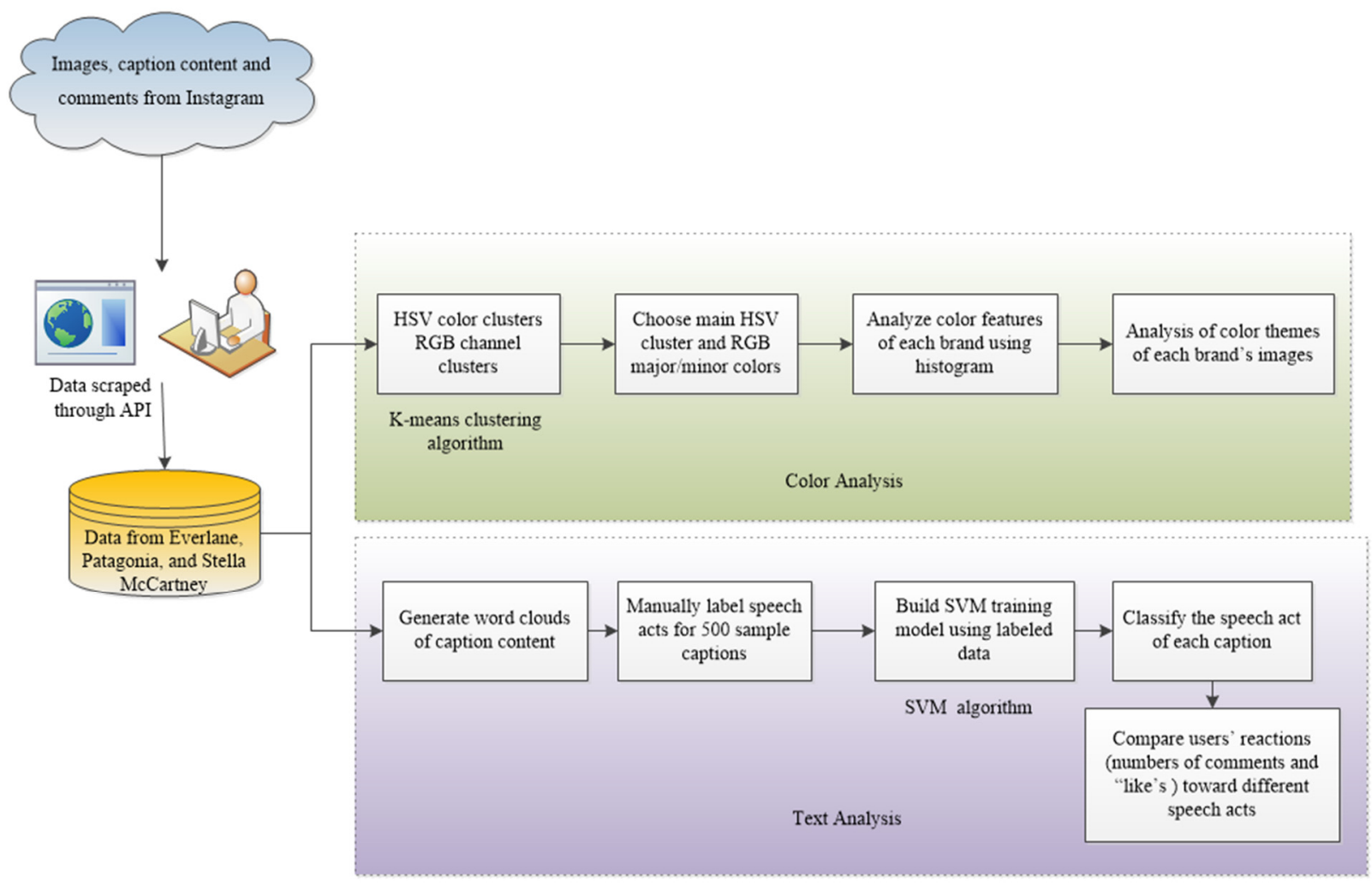

Figure 2. Research flow for data collection and analysis.

\section{Data Analysis and Results}

\subsection{RQ1. Color Features of Visual Information and Associated Caption Analysis}

To answer RQ1, we mainly used Instagram images and their associated captions posted by the three brands. Based on color theory, images from the three brands were analyzed in terms of their color features including Hue, Saturation, and Luminosity values (HSV). A K-means clustering algorithm was used to capture five colors clusters from images and extract their RGB features. We used the HSV clusters with the highest scores according to the main HSV features of each image, and RGB channel clusters with the highest two scores for the major and minor colors, respectively. To validate the tendencies of the images from each brand, the mean and standard deviation of the main HSV features and the mean values of the major and minor colors were calculated for each brand. Table 1 demonstrates the descriptive statistics of the color features of each brand. The saturation and luminosity of the main HSV features is consistent with the major and minor RGB channels. Hue could not represent the actual hue due to the average influence. 
Table 1. Descriptive statistics of the color features.

\begin{tabular}{llll}
\hline Color Features & Everlane & Patagonia & Stella McCartney \\
\hline Hue (mean/std) & $154 / 93$ & $116 / 94$ & $164 / 92$ \\
Saturation (mean/std) & $0.13 / 0.16$ & $0.30 / 0.27$ & $0.29 / 0.26$ \\
Luminosity (mean/std) & $0.76 / 0.23$ & $0.66 / 0.26$ & $0.64 / 0.28$ \\
Major color & $174,178,184$ & $140,140,135$ & $122,129,141$ \\
Minor color & $148,151,157$ & $131,130,127$ & $117,125,141$ \\
\hline
\end{tabular}

Three images were randomly selected from each brand's posts, and the five color clusters of the images are shown in Figure 3 as examples of the brief color themes of the three brands. The colors are displaced by descending scores. Hence, the color clusters of the Everlane images present mainly neutral colors focusing on lifestyle images. The color clusters of the Patagonia images mainly feature white, dark blue, and bright colors, as their images consist of landscapes and scenery, while the Stella McCartney images present a variety of colors concentrating on their products.

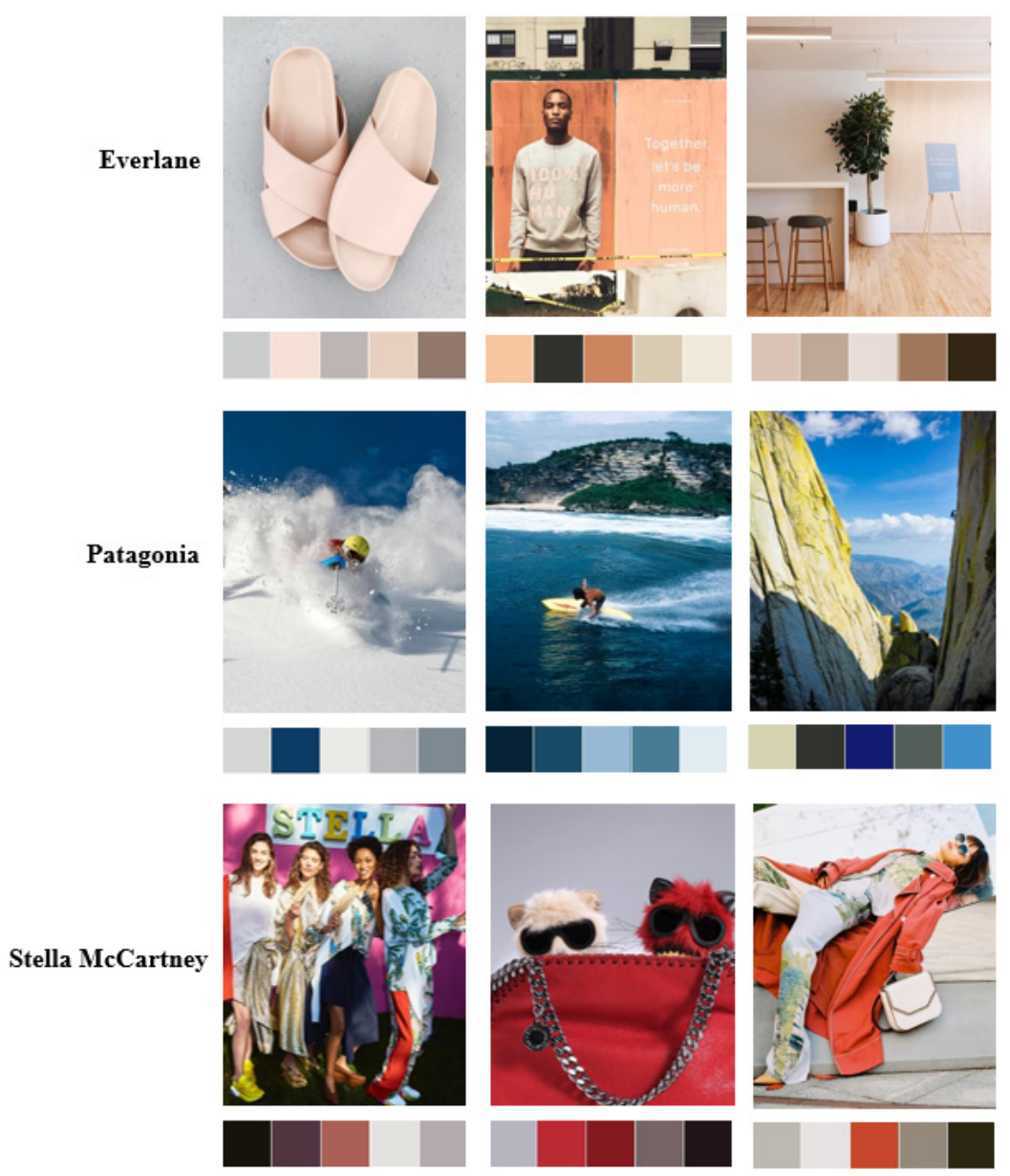

Figure 3. Examples of the five color clusters of each brand's images.

Figure 4 indicates the details of the color features for each brand using histograms, which explain the distribution of hue, saturation, and luminosity, respectively. When the saturation is 0 , the color is pure neural. As shown in Figure 4, the $x$-axis is the 10 bins of the dominant value of hue, saturation, and luminosity in each image, while the $y$-axis 
reflects the frequency of images for each brand. A neutral color represents a color with no identifiable hue; pure neutral colors are usually white, black, or gray.
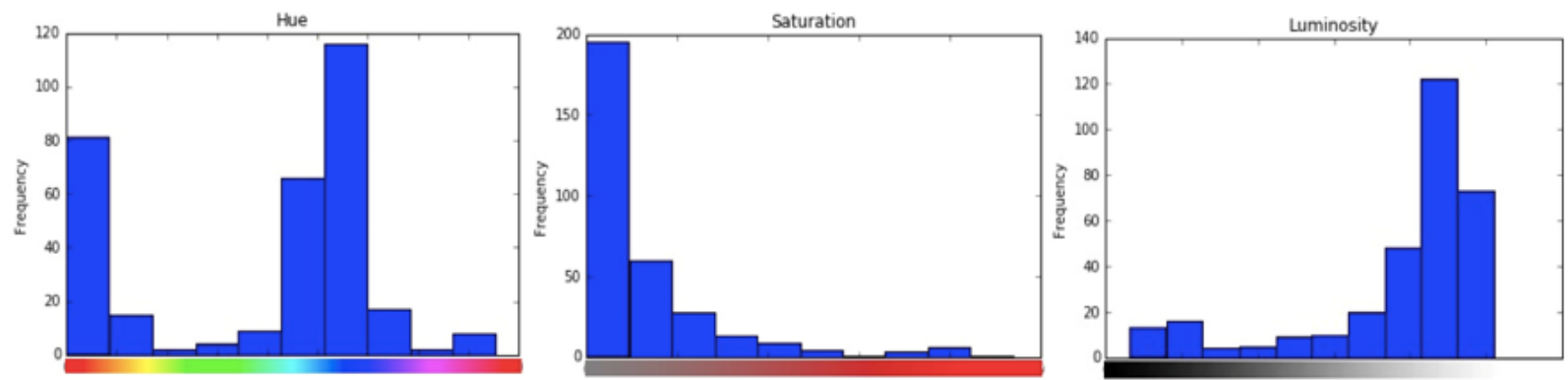

Distribution of hue, saturation and luminosity of Everlane images
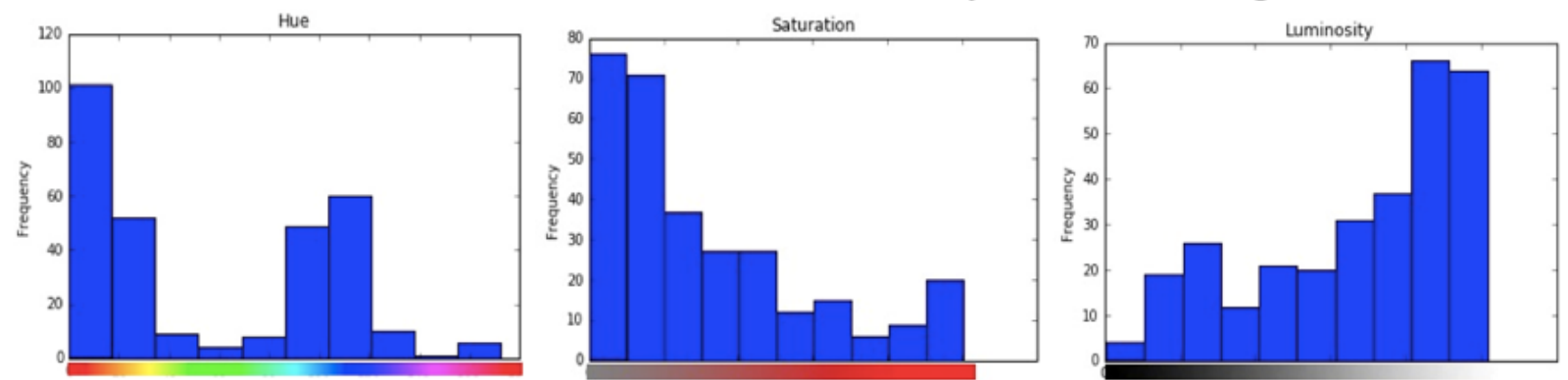

Distribution of hue, saturation and luminosity of Patagonia images
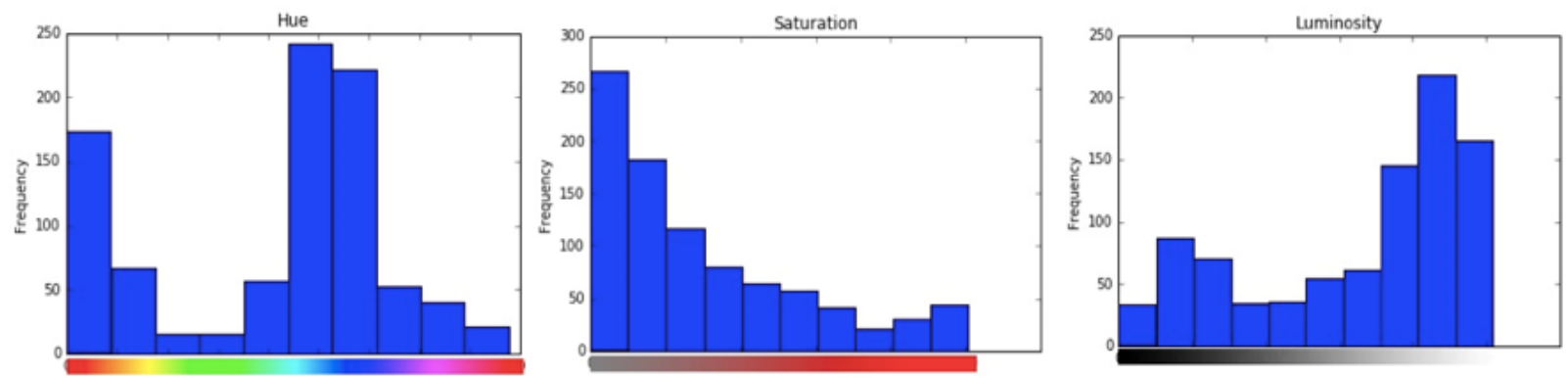

Figure 4. Distribution of the HSV of the three brands.

In addition to the visual information, the associated captions aligned with the images were analyzed to explore how visual and textual information work in collaboration. Therefore, to analyze the associated captions, word clouds were used to provide an intuitive and visually appealing overview of the text, depicting the words that occur most frequently in the captions [50]. In word clouds, font size is positively correlated with word frequency. The bigger a word gets, the more frequently it is mentioned. The three brands' word clouds are shown in Figure 5. Interestingly, although these three brands are known to heavily engage in sustainability, each brand's captions focused on different topics and values.
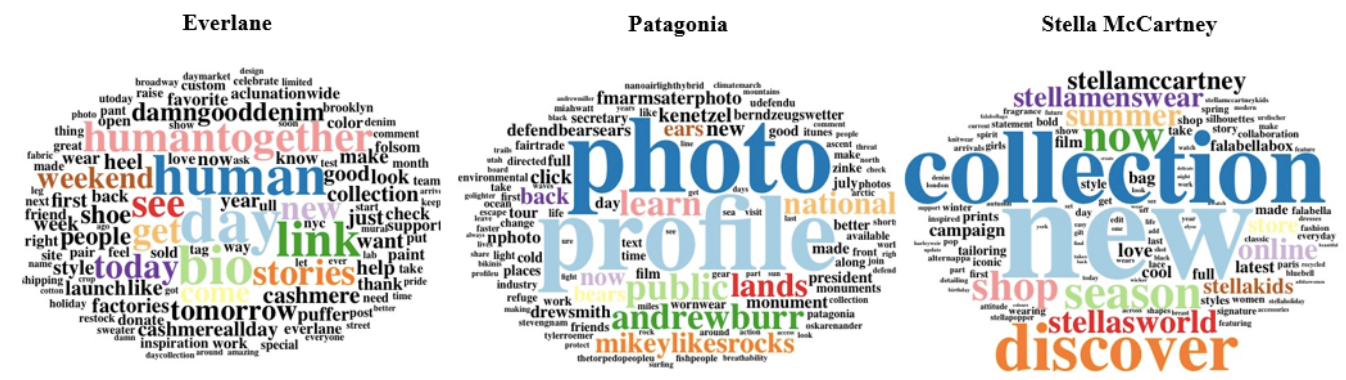

Figure 5. Word clouds of captions. 
Together with the captions, the messages related to sustainability were interpreted from the HSV information taken from the images. For Everlane, more than half of the images had the lowest level of saturation, which indicates a predominant use of neutral colors. Hue distribution presents a predominance of red and blue series colors. Most of Everlane's products feature basic styles in neutral colors. This is consistent with Everlane's vision, to "build the world's best high-quality basics." Choosing neutral colors for their products will allow consumers to keep items longer, which reflects the slow fashion philosophy [51]. At the same time, their captions contain 'humantogether' and 'people' messages. Everlane focuses on the social aspects of sustainability, citing humans, people, togetherness, bios, factories, etc. Everlane established their business as having "radical transparency", which means that they disclose the price of the labor and materials that go into each product, the factories they use, and the working conditions of the people who make their products [52]. The HSV of Everlane's images delivers a feeling of calm and care. Everlane's sustainability initiatives demonstrate the same message, which is about caring for the people in the supply chain and reducing waste through slow fashion practices [51].

Patagonia uses more low-level luminosity values in their images than Everlane since Patagonia posts abundant landscapes and scenic pictures in wild places. When the images show mainly dark forests and mountains, the luminosity is low, emphasizing the mystery of these environments. The luminosity is quite high if the images focus more on ocean waves and snow, highlighting the purity of the environment. The variant saturation values also depend on the diversity of the scenes depicted. Patagonia is famous for outdoor sports products, and their target customers take a great interest in athletics and green technology. The main content of Patagonia's pictures features the wildness of nature, as well as how people survive outdoors using Patagonia products. The images emphasize scenic characteristics more than people. This implies that Patagonia strives to convey that people are not owners of but a part of nature. The pictures of wild places show Patagonia's attention to and affection towards the clean natural environment without pollution, not only showing the courage and perseverance of people facing the wild natural world, but also aligning with their mission to "Build the best product, cause no unnecessary harm, use business to inspire and implement solutions to the environmental crisis" [53]. Patagonia's captions use words like public, lands, photos, learn, national, monument, president, and profile. In 2017, Patagonia had a campaign called “The President Stole Your Land" [54]. During that year, President Trump announced that he would cut back public lands, reducing almost two million acres in the Grand Staircase-Escalante National Monument and the Bears Ears National Monument [54]. This campaign aligned with Patagonia's business model of delivering a purpose-driven marketing strategy.

For Stella McCartney, the distribution of hue values is more average than for the other two brands, with more pink and green series colors. Stella McCartney has the most images with the lowest luminosity values, which means that black dominates. Figure 5 indicates that Stella McCartney images feature a variety of objects. The images show the different lifestyles of people using Stella McCartney products, as well as shocking landfills, and beautiful scenic and animal photos. This content is meant to convey the symbiosis of humans, nature, and animals to illustrate that protecting and caring for ourselves means nurturing and protecting the world that we live in. However, compared to Everlane and Patagonia, Stella McCartney doesn't deliver clear information about sustainability in their images. The primary words used in their captions are collection, new, discover, stellaworld, stellakids, and shop. Although Stella McCartney had a marketing campaign in Fall 2017 that was shot in a landfill, their captions that year mainly reflected words related to their new collection.

\subsection{RQ2. Text Features of Comments}

In order to achieve RQ2, 140,735 comments were analyzed. Five hundred sample text comments were randomly selected from the whole dataset, and the speech acts were manually labeled by two researchers in the fashion field. Posts with assertive acts were 
labeled as 1, expressive captions as 2 , and directive sentences were labeled as 3 . Among the 500 sample posts, 400 were randomly chosen as the training data; the remaining 100 were selected as testing data. Appearing more than 3 times in training data, 1271 unigrams were considered high-frequency words and were selected as predictors of speech acts. A supervised machine learning approach involving a support vector machine (SVM) [55] was used to analyze the training data. The e1071 library in R was installed and the internal svm() function in this library was used to conduct the SVM algorithm in this study. We also utilized the tune() function to select the best choice of parameters. Finally, we set the kernel to be "linear" and the cost at 10. In this study, we were only concerned about the speech acts in our own data set, and did not use any other data to pretrain the model.

The support vectors in this research consisted of 1271 words ( 1 if the word was present, 0 if not). A classification model was trained using the support vectors and training data through an SVM algorithm. This model was then applied to the testing data to verify its accuracy. Next, this model was utilized to predict the speech acts of the whole data set. The high-frequency words used in different speech acts were analyzed to explore the information and content that brands attempted to convey. The numbers of "likes" and user comments connected to different speech acts were compared using One-way ANOVA and Bonferroni tests to analyze the differences in user reactions.

The SVM model prediction accuracy of the testing data was $85 \%$, which means that the speech act prediction of 85 out of 100 testing posts was correct, consistent with previous research [55]. Table 2 shows the prediction results of the whole dataset of speech acts used by the three brands. Overall, directive acts dominated the posts from Everlane and Stella McCartney, while Patagonia used assertive acts most frequently. In posts using directive acts, the common high-frequency words utilized by all brands were "links", "discover", "find", "order", and so on. Directive acts were widely used to promote products and persuade users to click online ordering links. In Patagonia's posts involving directive acts, "public", "land", "wild", "defend", and "join" were also shown frequently. These words imply other information that Patagonia attempted to convey, which was to join an event to defend national wild lands and wild animals. Everlane used the words "cotton", "organic", and "cashmere" frequently in their directive posts to promote the sustainable materials contained in their products. The differences in number of users' comments and likes towards posts with different speech acts were also investigated. Table 3 shows the comparison of the number of comments on different speech acts and Table 4 shows the comparison of the number of "likes" for three speech acts. Overall, posts with expressive and directive acts were more likely to stimulate social media users to "comment" and "like".

According to the Bonferroni test results (Table 3), there were significant differences among all three brands in the number of comments when comparing posts with expressive and assertive acts and when comparing posts with directive and assertive acts. No significant differences were found when comparing posts with expressive and directive acts. These results indicate that social media users are more likely to leave comments on posts demonstrating expressive and directive acts. When users read posts with directive acts such as "discover the style in-store now", or "share your moments", and using expressive acts such as "Recipe for a perfect Sunday", they tend to post a reply, sharing their opinions and expressing their emotions. When they read posts employing assertive acts, such as "Winter is here" paired with a winter scene, they are less likely to reply. The comparison of the number of "likes" was quite similar to the number of comments. On the Stella McCarney and Patagonia Instagram pages, users tended to "like" more posts with expressive and directive acts rather than assertive acts. For Everlane, there did not seem to be a significant difference in which type of speech act generated more "likes".

It is not surprising that posts with directive acts generate more interactions among users. Many consumers today use social media pages as shopping platforms, so fashion brands that highlight their products and materials using a directive acts communication style will see more sales and increased engagement. Brands need to direct their audience as soon as possible to buy, choose, and try, etc. In this light, when promoting sustain- 
ability, identifying opinion leaders in the comments is extremely important to inspire other consumers to follow and act. In addition, the assertive acts communication style of Patagonia demonstrated that its target consumers respond to a certain method of persuasion. Their consumers take responsibility for being part of the brand's mission of protecting our environment. These results are useful in enabling sustainable brands to come up with better customer profiles and uncover the communication styles prevalent in consumer-to-consumer interactions.

Table 2. Speech acts used by three fashion brands.

\begin{tabular}{cccc}
\hline Speech Acts & Stella McCartney & Patagonia & Everlane \\
\hline Assertive & 226 & 156 & 99 \\
Expressive & 286 & 79 & 56 \\
Directive & 393 & 65 & 165 \\
\hline Total & 905 & 300 & 320 \\
\hline
\end{tabular}

Table 3. Comparison of number of comments on different speech acts.

\begin{tabular}{|c|c|c|c|c|c|c|c|}
\hline & \multirow{3}{*}{$\begin{array}{l}\text { One Way } \\
\text { ANOVA } \\
p \text {-Value }\end{array}$} & \multicolumn{6}{|c|}{ Bonferroni Test } \\
\hline & & \multicolumn{2}{|c|}{ Expressive vs. Assertive } & \multicolumn{2}{|c|}{ Directive vs. Assertive } & \multicolumn{2}{|c|}{ Expressive vs. Directive } \\
\hline & & $\begin{array}{c}\text { Mean } \\
\text { Difference }\end{array}$ & $p$-Value & $\begin{array}{c}\text { Mean } \\
\text { Difference }\end{array}$ & $p$-Value & $\begin{array}{c}\text { Mean } \\
\text { Difference }\end{array}$ & $p$-Value \\
\hline Stella-McCartney & 0.003 * & 25.6 & $0.01 *$ & 37.8 & $0.003 *$ & -12.2 & 0.5 \\
\hline Everlane & $0.005^{*}$ & 28.3 & $0.011 *$ & 19.1 & $0.029 *$ & 9.2 & 0.9 \\
\hline Patagonia & $<0.001 *$ & 39.6 & 0.003 * & 48.0 & $<0.001 *$ & -8.4 & 1 \\
\hline
\end{tabular}

Table 4. Comparison of "like" numbers on different speech acts.

\begin{tabular}{|c|c|c|c|c|c|c|c|}
\hline & \multirow{3}{*}{$\begin{array}{c}\text { One Way } \\
\text { ANOVA } \\
p \text {-Value }\end{array}$} & \multicolumn{6}{|c|}{ Bonferroni Test } \\
\hline & & \multicolumn{2}{|c|}{ Expressive vs. Assertive } & \multicolumn{2}{|c|}{ Directive vs. Assertive } & \multicolumn{2}{|c|}{ Expressive vs. Directive } \\
\hline & & $\begin{array}{c}\text { Mean } \\
\text { Difference }\end{array}$ & $p$-Value & $\begin{array}{c}\text { Mean } \\
\text { Difference }\end{array}$ & $p$-Value & $\begin{array}{c}\text { Mean } \\
\text { Difference }\end{array}$ & $p$-Value \\
\hline Stella-McCartney & $0.001 *$ & 3130.7 & 0.012 * & 4165.7 & $0.006^{*}$ & -1035.0 & 1 \\
\hline Everlane & 0.09 * & 1495.2 & 0.11 & 808.8 & 0.41 & 686.4 & 0.92 \\
\hline Patagonia & $0.005 *$ & 3669.5 & 0.041 * & 4633.9 & $0.018^{*}$ & -964.4 & 1 \\
\hline
\end{tabular}

${ }^{*} p<0.05$. Scores demonstrate the significant differences between the three groups.

\section{Conclusions}

By employing both color theory and the speech acts theory, this is the first study to explore how sustainable brands convey information on social media through data mining techniques. The findings demonstrate the efficiency and accuracy of this research schema in the field of fashion. Sustainable brands use both visual and textual information to deliver sustainable messages to their followers with the aim of enhancing customer engagement. In general, the images and captions posted by all three brands were consistent with their brand identities and sustainability goals $[19,24]$. HSV was important information to apply in interpreting Instagram images. Its application is especially effective for fashion brands, as color is one of the most important elements of any fashion product. Everlane emphasized social responsibility, using eco-friendly materials such as natural fibers, and slow fashion practices [51]. Patagonia engaged followers with high-quality photos of natural scenery, and its sustainability efforts focused more on environmental concerns. Stella McCartney's Instagram posts demonstrated their identity as a luxury brand. However, their posts did 
not overtly emphasize sustainability, which was quite surprising. Fashion brands that strive to promote sustainability on social media need to establish a clear agenda with appropriate images and posts to best represent their sustainable development goals [56]. At the same time, it is important to determine the types of posts that will generate customer engagement. Using different images and speech acts may change consumer responses [44]. Advocating for sustainability does not necessarily require a 'call to action' strategy. Fashion brands may incorporate relevant messages when promoting sustainable products like Everlane does, or post high-quality images containing indirect messages to remind consumers of the beauty of the natural environment like Patagonia. Third, besides paying attention to posts from brands, it is also important to monitor consumer-to-consumer interactions and participate in comments. Such communications may help interpret messages from brands and build community.

In addition, the findings suggest that sustainable brands prefer to use different speech acts in their textual posts $[42,43]$. Instead of manually coding the whole dataset, the SVM classification model was used to reduce time as well as to maintain relatively high accuracy. Amongst the three brands examined, the posts and comments from Stella McCartney did not prominently feature sustainability-related messages. This implies that some sustainable brands do not actively promote sustainability via social media. On the other hand, Everlane and Stella McCartney used directive acts to advertise products and promote events. Patagonia used assertive and expressive acts paired with images of wild mountains and forests to convey their values. Expressive acts consist of affective terms, so posts demonstrating these acts could easily arouse audiences' emotions [45]. Posts with directive acts are usually a call to action, so the audience will be more likely to leave a reaction. This implies that Everlane and Patagonia are more active in exploiting social media by communicating their values around sustainabilty. This finding provides guidance to other fashion brands striving to concentrate on sustainabilitiy. When brands choose to use social media as a tool and sustainability as a marketing opportunity, it is important to have a strategy that is consistent with the brand's identity [44]. Having consistent themes can help followers to remember brands' unique sustainability goals. Therefore, it is important for fashion social media marketers to choose appropriate speech acts when delivering information.

There are limitations to this study that could lead to future research opportunities. First, since this study focused on the past paths of three chosen brands, the data is not up to date. With the system established in this study, up-to-date data can be fed into the next phase to optimize the system and provide more insights into current trends and behavior. Second, this research schema could be applied to investigations of other fast fashion brands or small designer brands for comparison. This could be particularly important for fast fashion brands, as they are usually considered non-sustainable. It would be interesting to explore how different types of fashion brands could better communicate with their target consumers on social media, and how consumers may drive the charge and demand that fashion brands put more effort into sustainability. In addition, the in-depth relationship between posts and comments can be further investigated through other qualitative and quantitative approaches, such as conducting interviews and experiments. When consumers see a certain message from a fashion brand, what are the brand associations related to sustainability and what motived them to engage with this brand? It is also important to explore the intentions of brands' posts on social media from the brands' perspective and to evaluate the effectiveness of their communications. Moreover, other computer vision techniques can be used to analyze Instagram images. Besides utilizing certain colors, images may be constructed to communicate other important information related to sustainability.

Author Contributions: Conceptualization, L.Z.; Methodology, L.Z., M.L., P.S.; Formal Analysis, L.Z., M.L., P.S.; Writing—Original Draft Preparation, L.Z., S.H.L.; Writing—Review \& Editing, L.Z., S.H.L. All authors have read and agreed to the published version of the manuscript.

Funding: This research received no external funding.

Institutional Review Board Statement: Not applicable. 


\section{Informed Consent Statement: Not applicable.}

Data Availability Statement: Not applicable.

Conflicts of Interest: The authors declare no conflict of interest.

\section{References}

1. Vanauken, K. Using social media to improve customer engagement and promote products and services. J. Air Manag. 2015, 9, 109-117.

2. Reilly, A.H.; Hynan, K.A. Corporate communication, sustainability, and social media: It's not easy (really) being green. Bus. Horiz. 2014, 57, 747-758. [CrossRef]

3. Reiter, L.; Kozar, J. Chinese Students' Knowledge of Environmentally and Socially Sustainable Apparel and Sustainable Purchase Intentions. Int. J. Mark. Stud. 2016, 8, 12. [CrossRef]

4. Han, S.L.-C.; Henninger, C.E.; Apeagyei, P.; Tyler, D. Determining Effective Sustainable Fashion Communication Strategies. In Sustainability in Fashion; Springer International Publishing: Cham, Switzerland, 2017; pp. 127-149. [CrossRef]

5. McNeill, L.; Moore, R. Sustainable fashion consumption and the fast fashion conundrum: Fashionable consumers and attitudes to sustainability in clothing choice. Int. J. Consum. Stud. 2015, 39, 212-222. [CrossRef]

6. Schivinski, B.; Dabrowski, D. The effect of social media communication on consumer perceptions of brands. J. Mark. Commun. 2016, 22, 189-214. [CrossRef]

7. Erdoğmuş, I.E.; Çiçek, M. The Impact of Social Media Marketing on Brand Loyalty. Procedia Soc. Behav. Sci. 2012, 58, 1353-1360. [CrossRef]

8. Phan, M.; Thomas, R.; Heine, K. Social Media and Luxury Brand Management: The Case of Burberry. J. Glob. Fash. Mark. 2011, 2, 213-222. [CrossRef]

9. Hu, Y.; Manikonda, L.; Kambhampati, S. What We Instagram: A First Analysis of Instagram Photo Content and User Types. In Proceedings of the Eighth International AAAI Conference on Weblogs and Social Media, Ann Arbor, MI, USA, 1-4 June 2014; pp. 595-598.

10. Roncha, A.; Radclyffe-Thomas, N. How TOMS' "one day without shoes" campaign brings stakeholders together and co-creates value for the brand using Instagram as a platform. J. Fash. Mark. Manag. Int. J. 2016, 20, 300-321. [CrossRef]

11. Elkington, J. Cannibals with Forks-Triple Bottom Line of 21st Century Business; New Society Publishers: Stoney Creek, CT, USA, 1997.

12. Brundtland, G. Report of the World Commission on Environment and Development: Our Common Future; United Nations General Assembly Document, A/42/427; Oxford University Press: Oxford, UK, 1987.

13. Yan, W.; Chen, C.-H.; Chang, W. An investigation into sustainable product conceptualization using a design knowledge hierarchy and Hopfield network. Comput. Ind. Eng. 2009, 56, 1617-1626. [CrossRef]

14. Goel, P. Triple bottom line reporting: An analytical approach for corporate sustainability. J. Financ. Account. Manag. 2010, 1, 27-42.

15. Milnes, H. Everlane's Social Strategy: Drive Community Engagement, Not Sales. Available online: https://digiday.com/ marketing/everlanes-social-strategy-drive-community-engagement-not-sales/ (accessed on 10 December 2021).

16. De Lenne, O.; Vandenbosch, L. Media and sustainable apparel buying intention. J. Fash. Mark. Manag. Int. J. 2017, 21, 483-498. [CrossRef]

17. Goh, K.-Y.; Heng, C.-S.; Lin, Z. Social Media Brand Community and Consumer Behavior: Quantifying the Relative Impact of User- and Marketer-Generated Content. Inf. Syst. Res. 2013, 24, 88-107. [CrossRef]

18. Stelzner, M.A. 2010 Social Media Marketing Industry Report: How Marketers Are Using Social Media to Grow Their Businesses. Available online: http:/ / designdamage.com/wp-content/uploads/2009/04/SocialMediaMarketingReport2010.pdf (accessed on 10 December 2021).

19. Amencherla, M.; Varshney, L.R. Color-based visual sentiment for social communication. In Proceedings of the 201715 th Canadian Workshop on Information Theory (CWIT), Quebec, QC, Canada, 11-14 June 2017; pp. 1-5.

20. Ha, Y.-I.; Kwon, S.; Cha, M.; Joo, J. Fashion conversation data on Instagram. Presented at the ICWSM'17. arXiv 2017, arXiv:1704.04137.

21. Agoston, G.A. Color Theory and Its Application in Art and Design. In Springer Series in Optical Sciences; MacAdam, D.L., Ed.; Springer: Berlin/Heidelberg, Germany; New York, NY, USA, 2013.

22. Gorn, G.J.; Chattopadhyay, A.; Sengupta, J.; Tripathi, S. Waiting for the Web: How Screen Color Affects Time Perception. J. Mark. Res. 2004, 41, 215-225. [CrossRef]

23. Roullet, B. L'influence de la Couleur en Marketing: Vers une Neuropsychologie du Consommateur. Available online: https: / / tel.archives-ouvertes.fr/tel-00208003/document (accessed on 1 May 2020).

24. Lichtle, M.-C. The Effect of an advertisement's colour on emotions evoked by an ad and attitude towards the ad: The moderating role of the optimal stimulation level. Int. J. Advert. 2007, 26, 37. [CrossRef]

25. Bottomley, P.A.; Doyle, J.R. The interactive effects of colors and products on perceptions of brand logo appropriateness. Mark. Theory 2006, 6, 63-83. [CrossRef]

26. Singh, S. Impact of color on marketing. Manag. Decis. 2006, 44, 783-789. [CrossRef] 
27. Spence, C.; Puccinelli, N.; Grewal, D.; Roggeveen, A.L. Store Atmospherics: A Multisensory Perspective. Psychol. Mark. 2014, 31, 472-488. [CrossRef]

28. Droulers, O.; Roullet, B. Émergence du neuromarketing: Apports et perspectives pour les praticiens et les chercheurs. Decis. Mark. 2007, 46, 9-22. [CrossRef]

29. Caivano, J.L. Research on color in architecture and environmental design: Brief history, current developments, and possible future. Color Res. Appl. 2006, 31, 350-363. [CrossRef]

30. Deng, X.; Hui, S.K.; Hutchinson, J.W. Consumer preferences for color combinations: An empirical analysis of similarity-based color relationships. J. Consum. Psychol. 2010, 20, 476-484. [CrossRef]

31. Habel, R.; Kudenov, M.; Wimmer, M. Practical Spectral Photography. Comput. Graph. Forum 2012, 31, 449-458. [CrossRef]

32. Divard, R.; Urien, B. Le consommateur vit dans un monde en couleurs. Rech. Appl. Mark. 2001, 16, 3-24. [CrossRef]

33. Rex, J.; Wai, S.; Lobo, A. An Exploratory Study into the Impact of Colour and Packaging as Stimuli in the Decision-Making Process for a Low Involvement Non-Durable Product. In Proceedings of the Australian and New Zealand Marketing Academy Conference, University of Wellington, Wellington, New Zealand, 29 November-1 December 2004.

34. Kaya, N.; Epps, H.H. Relationship between color and emotion: A study of college students. Coll. Stud. J. 2004, $38,396$.

35. Martinez, L.M.; Rando, B.; Agante, L.; Abreu, A.M. True colors: Consumers' packaging choices depend on the color of retail environment. J. Retail. Consum. Serv. 2020, 59, 102372. [CrossRef]

36. Bagchi, R.; Cheema, A. The Effect of Red Background Color on Willingness-to-Pay: The Moderating Role of Selling Mechanism. J. Consum. Res. 2012, 39, 947-960. [CrossRef]

37. Bellizzi, J.A.; Hite, R.E. Environmental color, consumer feelings, and purchase likelihood. Psychol. Mark. 1992, 9, 347-363. [CrossRef]

38. Elliot, A.J.; Maier, M.A. Chapter two-Color-in-context theory. In Advances in Experimental Social Psychology; Devine, P., Plant, A., Eds.; Academic Press: Oxford, UK, 2012; Volume 45, pp. 61-125.

39. Aslam, M.M. Are You Selling the Right Colour? A Cross-Cultural Review of Colour as a Marketing Cue. J. Mark. Commun. 2006, 12, 15-30. [CrossRef]

40. Searle, J.; Kiefer, F.; Bierwisch, M. Speech Act Theory and Pragmatics; Springer: Dordrecht, The Netherlands, 1980; Volume 10. [CrossRef]

41. Krippendorff, K. Content Analysis: An Introduction to Its Methodology, 3rd ed.; Sage Publications: Thousand Oaks, CA, USA, 2004; p. 412.

42. Ansari, S.; Gupta, S. Customer perception of the deceptiveness of online product reviews: A speech act theory perspective. Int. J. Inf. Manag. 2021, 57, 102286. [CrossRef]

43. Ordenes, F.V.; Ludwig, S.; De Ruyter, K.; Grewal, D.; Wetzels, M. Unveiling What Is Written in the Stars: Analyzing Explicit, Implicit and Discourse Patterns of Sentiment in Social Media. J. Consum. Res. 2017, 43, 875-894. [CrossRef]

44. Ordenes, F.V.; Grewal, D.; Ludwig, S.; De Ruyter, K.; Mahr, D.; Wetzels, M. Cutting through Content Clutter: How Speech and Image Acts Drive Consumer Sharing of Social Media Brand Messages. J. Consum. Res. 2019, 45, 988-1012. [CrossRef]

45. Cui, C.; Mao, W. Recognize user intents in online interactions from massive social media data. In Proceedings of the 2017 IEEE 2nd International Conference on Big Data Analysis (ICBDA), Beijing, China, 10-12 March 2017; pp. 11-15. [CrossRef]

46. Ludwig, S.; de Ruyter, K. Decoding social media speak: Developing a speech act theory research agenda. J. Consum. Mark. 2016, 33, 124-134. [CrossRef]

47. Gergen, K.J.; Thatchenkery, T.J. Organization Science as Social Construction. J. Appl. Behav. Sci. 2004, 40, 228-249. [CrossRef]

48. Aleti, T.; Pallant, J.; Tuan, A.; van Laer, T. Tweeting with the Stars: Automated Text Analysis of the Effect of Celebrity Social Media Communications on Consumer Word of Mouth. J. Interact. Mark. 2019, 48, 17-32. [CrossRef]

49. eMarketer. Global Instagram Users 2020: The Pandemic Propels Worldwide User Base to 1.00 Billion for the First Time. Available online: https:/ / www.emarketer.com/content/global-instagram-users-2020 (accessed on 10 December 2021).

50. Heimerl, F.; Lohmann, S.; Lange, S.; Ertl, T. Word Cloud Explorer: Text Analytics Based on Word Clouds. In Proceedings of the 47th Hawaii International Conference on System Sciences, Hilton Waikoloa, HI, USA, 6-9 January 2014; IEEE: Waikoloa, HI, USA, 2014; pp. 1833-1842. [CrossRef]

51. Everlane.com. About Us. Available online: https://www.everlane.com/about (accessed on 10 December 2021).

52. Hershman, H.; Mills, E. Everlane is a Millennial Fever Dream and It's Making a Killing. Available online: https://www. marketplace.org/2017/06/09/ everlane-millennial-fever-dream-and-its-making-killing/ (accessed on 10 December 2021).

53. Patagonia.com. Activism. Available online: https://www.patagonia.com/activism/ (accessed on 10 December 2021).

54. Andrews, T.M. The President Stole Your Land: Patagonia, REI Blast Trump on National Monument Rollbacks. Available online: https:/ / www.washingtonpost.com/news/morning-mix/wp/2017/12/05/the-president-stole-your-land-patagoniarei-blast-trump-on-national-monument-rollbacks / (accessed on 10 December 2021).

55. Zhang, R.; Gao, D.; Li, W. What are Tweeters Doing: Recognizing Speech Acts in Twitter. In Proceedings of the 5th AAAI Conference on Analyzing Microtext (AAAIWS' 11-05), San Francisco, CA, USA, 8 August 2011; pp. 86-91.

56. Kong, H.M.; Witmaier, A.; Ko, E. Sustainability and social media communication: How consumers respond to marketing efforts of luxury and non-luxury fashion brands. J. Bus. Res. 2021, 131, 640-651. [CrossRef] 